BIODIK: Jurnal IImiah Pendidikan Biologi
ISSN 2580-0922 (online), ISSN 2460-2612 (print)
Volume 7, Nomor 01, Tahun 2021, Hal. 77-83
Available online at:
https://online-journal.unja.ac.id/biodik

Research Article

open 2 ACcess

\title{
Efektivitas Model Blended Learning Terhadap Hasil Belajar Mahasiswa Pada Mata Kuliah Zoologi di Era Covid-19
}

\section{(The Effectiveness of the Blended Learning Model on Student Learning Outcomes in Zoology Subjects in the Covid-19 Era)}

\author{
Tomi Apra Santosa*, Abdul Razak, Azwir Anhar, Ramadhan Sumarmin \\ Magister Pendidikan Biologi, Universitas Negeri Padang \\ JI. Prof. Dr. Hamka, Air Tawar Bar. Kota Padang, Sumatera Barat 25171-Indonesia \\ Corresponding Authors : santosatomiapra@gmail.com
}

\begin{tabular}{|c|c|}
\hline Informasi Artikel & ABSTRACT \\
\hline $\begin{array}{l}\text { Submit: } 24-12-2020 \\
\text { Diterima: } 28-02-2021 \\
\text { Dipublikasikan: } 15-03-2021\end{array}$ & $\begin{array}{l}\text { The purpose of this study was to determine the differences between the blended } \\
\text { learning and offline method models on student learning outcomes in the COVID-19 } \\
\text { pandemic. The research used was experimental. The research subjects came from 5- } \\
\text { semester biology tadris students of the } 2019 / 2020 \text { academic year IAIN Kerinci. } \\
\text { Research instruments in the form of tests and questionnaires via a google form. The } \\
\text { data analysis technique was in the form of the t-test with Minitab } 19 \text { software. To } \\
\text { carry out the hypothesis test, the normality test and the homogeneity test had to be } \\
\text { done first. The results showed that the blended learning model was effective in } \\
\text { increasing student learning outcomes in the zoology course by an average of } 68.16 \\
\text { to 83.42. and provide a significant effect of the blended learning model on student } \\
\text { learning outcomes in zoology material. This can be seen from the p-value of 0.000 } \\
<0.05 \text {. The blended learning model is very good to be applied in schools even in } \\
\text { universities where this learning model is able to improve student learning outcomes in } \\
\text { the era of the COVID-19 pandemic. } \\
\text { Key words: Blended Learning, Learning Outcomes, Student Motivation, COVID-19 }\end{array}$ \\
\hline Penerbit & ABSTRAK \\
\hline $\begin{array}{l}\text { Program Studi Pendidikan } \\
\text { Biologi, Fakultas Keguruan dan } \\
\text { Ilmu Pendidikan, Universitas } \\
\text { Jambi }\end{array}$ & $\begin{array}{l}\text { Tujuan penelitian ini mengetahui perbedaan model blended learning dan luring } \\
\text { method terhadap hasil belajar biologi siswa pada pandemi COVID-19. Penelitian } \\
\text { yang digunakan eksperimen. Subjek penelitian berasal dari mahasiswa tadris biologi } \\
\text { semester } 5 \text { tahun ajaran } 2019 / 2020 \text { IAIN Kerinci. Instrumen penelitian berupa tes } \\
\text { dan angket melalui google form. Teknis analisis data berupa uji } t \text { dengan sofware } \\
\text { Minitab } 19 \text {. Untuk melaksanakan uji hipotesis, maka harus dilakukan dahulu uji } \\
\text { normalitas dan uji homegenitas data. Hasil penelitian menunjukan bahwa model } \\
\text { blended learning efektif meningkatan hasil belajar mahasiswa pada mata kuliah } \\
\text { zoologi dengan rata-rata } 68.16 \text { menjadi } 83.42 \text {. dan memberikan pengaruh signifikan } \\
\text { model blenden learning terhadap hasil belajar mahasiswa pada materi zoologi. Hal } \\
\text { dapat dilihat dari nilai p-value } 0.000<0.05 \text {. Model blended learning sangat baik untuk } \\
\text { diterapkan di sekolah bahkan di perguruan tinggi dimana model pembelajaran ini } \\
\text { mampu meningkatkan hasil belajar mahasiswa di era pendemi covid } 19 \text {. } \\
\text { Kata kunci: Blended Learning, Hasil Belajar, Motivasi Siswa, COVID-19 }\end{array}$ \\
\hline
\end{tabular}




\section{PENDAHULUAN}

Kemajuan pada Abad-21 telah memberikan dampak yang besar terhadap sistem pendidikan di Inonesia. Pendidikan di abad -21 atau revolusi industri 4. untuk menghadapi berbagai tantangan globalisasi (Susilo \& Solfiarini, 2020). Pola pendidikan era globalisasi menggunakan media pembelajaran berbasis teknologi (Mailani et.al., 2020). Untuk melihat kemajuan kualitas pendidikan di perguruan dapat dilihat dari Rough Participation Index (RPI). Pada tahun 2015 perguruan tinggi Indonesia memiliki nilai RPI sebesar $26,86 \%$ yang masih rendah di bandingkan dengan negara ASEAN lainnya (Effendi, 2017). Hal perlu dilakukan pemerintah adalah meningkatkan kualitas hard skill dan soff skil manusianya. Karena di perguruan tinggi di hanya meningkatkan kapasitas akademik, akan tetapi bagaimana partisipasi untuk masa depannya (Chiou, 2018).

Musibah Covid-19 memberikan dampak dari berbagai aspek kehidupan termasuk perguruan tinggi (( Ambarita et.al., 2020; Sadikin et al., 2020). Pandemi Covid-19 mengalami peningkatan setiap hari beberapa negara di dunia menutup pintu masuk untuk wisatawan asing dan melakukan karantina mandir dan menyebabkan krisis pembelajaran ( Koçoğlu \& Tekdal, 2020; lyengar, 2020). (Koçoğlu \& Tekdal, 2020). Pemerintah menutup semua sekolah sampai wabah Covid-19 ini hilang (Aowad et al., 2020). Menurut UNESCO penutupan sekolah mempengaruhi $90 \%$ atau 1,5 milliar populasi peserta didik dunia (Ciğerci, 2020). Hal Ini dapat mempengaruhi perhatian dan prestasi akademik mahasiswa (Kaya, 2020). Pendidik harus melakukan pembelajaran jarak jauh. Pembelajaran jarak jauh menjadi pembelajaran yang paling di senangi seluruh dunia pada masa Covid-19 ini (Karakaya et al., 2020).

Pembelajaran jarak jauh atau daring tidak sepenuhya berjalan efektif. Masalahnya tidak semua peserta didik mampu melaksanakan pembelajaran daring (Al-nofaie, 2020).Pembelajaran di era revolusi 4.0 melalui daring memiliki karakteristik setiap pendidik dan peserta didik mampu dalam meningkatkan ketrampilan dan inovasi dalam menguasai teknologi (Sumardi et.al., 2020; Ayu et al., 2020; (Ujir et al., 2020). Selain itu, perlu adanya peningkatan keefektifan terhadap pelaksanaan, tidak hanya berkaitan dengan teknis dan fasilitas internet (Önal \& Önal, 2020). Namun, perbaikan masalah ini akan memberikan yang efektif terhadapat kegiatan belajar peserta didik. Hasil belajar menentukan tingkat kemampuan peserta dalam memahami konsep dan materi pembelajaran yang telah diberikan oleh pendidik. Pendidikan yang profesional akan melakukan inovasi dan kalaborasi model maupun metode belajar yang tepat digunakan pada saat ini.

Biologi adalah ilmu pengetahuan yang menelaah tentang makhluk hidup di sekitar kita (Shen et al., 2018). Biologi memiliki banyak cabang ilmu termasuk zoologi yang diharapkan peserta didik mampu memahami (Carvalho, 2020). Zoologi adalah ilmu yang mempelajari tentang hewan. Zoologi menjadi mata kuliah wajib pada perguruan tinggi. Keberhasilan peserta didik dalam mempelajari zoologi ditentukan oleh pendidik yang di mengajar di kelas. Pendidik dapat mengaplikasikan materi kepada siswa agar mudah dipahami. Kendala yang di hadapi peserta didik dalam belajar daring ini adalah kurang efektivitas pendidik dalam menyampaikan materi zoologi. Oleh karena itu, adanya model pembelajaran daring yang mampu meningkatkan pemahaman pendidik dalam menyampaikan materi pelajaran.

Blended learning adalah model pembelajaran campuran yang dapat di lakukan secara tatap muka dan daring (Sari, 2012). Blended learning bagus diterapkan dalam belajar zoologi. Karena model ini mampu membuat pembelajaran lebih bermakna karena siswa dapat dengan mudah memahami materi pelajaran yang telah dilakukan (Sandi, 2012). Model blended learning dapat dilaksanakan pada 
masa Covid-19 dengan kategori daerah yang termasuk zona kuning atau hijau. Peserta didik dan pendidik mampu menjalin hubungan yang lebih efetktif dalam pembelajaran online (Yanti et.al., 2019).

Berdasarkan penelitian Shamsuddin \& Kaur ( 2019) blended learning berpengaruh terhadap antara gaya belajar dan persepsi siswa. Penelitian Quinn \& Aarao (2020) blended learning mampu mengendali diri ssiwa dalam pembelajaran matematika. Penelitian oleh Syarif (2012) bahwa model blended learning mampu mendorong motivasi dan prestasi belajar peserta didik. Penelitian Fitri, dkk (2016) bahwa pemberian layanan dengan metode blended learning mampu mendorong motivasi peserta menjadi lebih efektif. Penelitian Sandi (2016) bahwa model blended learning mampu meningkatkan hasil belajar kimia siswa. Berdasarkan masalah di atas penelitian ini bertujuan untuk mengetahui efektivitas model blended learninf terhadap hasil belajar mahasiswa pada mata kuliah zoologi.

\section{METODE PENELITIAN}

Penelitian yang digunakan adalah penelitian quasi eksperimen dengan model non equivalent control grup. Populasi berasal dari mahasiswa tadris biologi IAIN Kerinci semester 5 tahun ajaran 2019/2020 yang terdiri dari 4 Kelas. Pemilihan sampel dengan teknik purposive sampling. Pengambilan sampel tersebut memperhatikan siswa-siswa yang telah menguasai materi zoologi. Sampel yang dijadikan yakni kelas VA untuk kelas eksperimen berjumlah 16 orang dan Kelas VC untuk kelas kontrol berjumlah 12 orang. Kelas eksperimen mengunakan model blended learning dan kelas kontrol model konvensional. Instrumen penelitian yang dipakai yaitu tes yang kirim melalui google form. Teknik analisis data adalah uji t dengan aplikasi sofware minitab 19.

\section{HASIL PENELITIAN DAN PEMBAHASAN}

Pada kelas eksperimen kegiatan belajar mengajar menggunakan model blended learrning. Kegiatan ini dilakukan dengan tatap muka sebanyak 8 kali selama 40 menit dan dengan menggunakan online learning dengan zoom meet sebanyak 8 kali selama 40 menit. Untuk kelas kontrol menggunakan metode konvensional dengan kegiatan belajar mengajarkan dilakukan selama 40 menit.

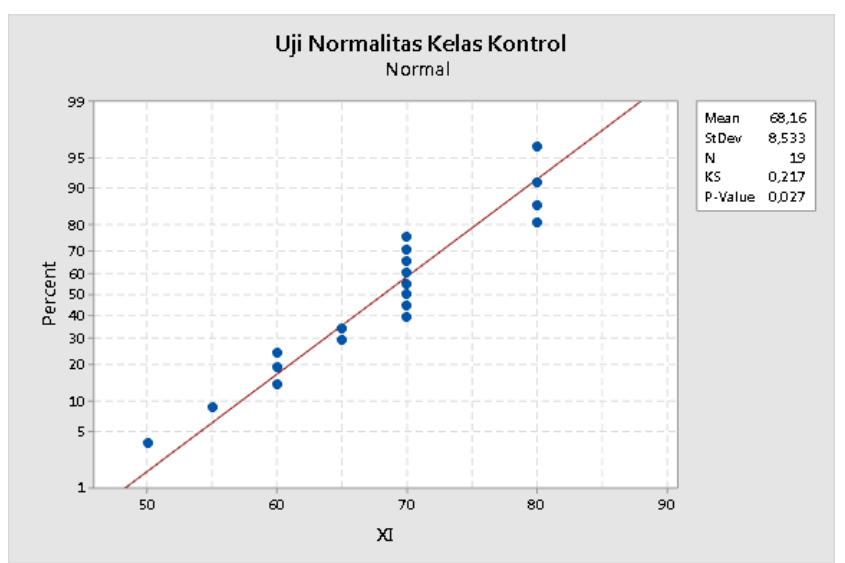

Gambar.1 Uji Normalitas Kelas Kontrol 
Berdasarkan tabel di atas nilai rata-rata (mean) uji Kolmogorov-Smirnov pada kelas kontrol 68.16, standar devisiasi 0.533 dan nilai P-Value $0.027>0.05$ menunjukan bahwa data dari kelas kontrol berdistribusi normal.

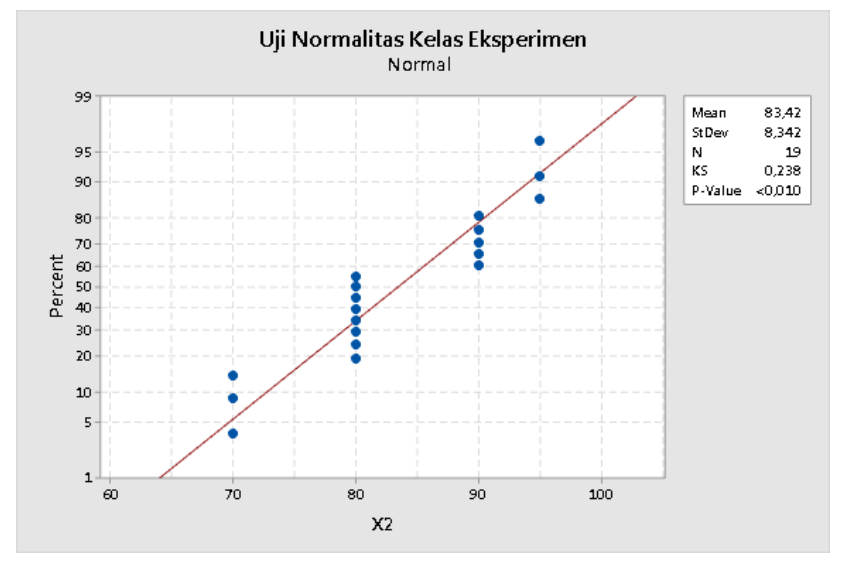

Gambar.1 Uji Normalitas Kelas Eksperimen

Berdasarkan tabel di atas menunjukan nilai rata-rata (mean) kelas eksperimen 83,42, standar deviasi 0.342 dan nilai P-Value $0.010>0.05$, maka dapat dikatakan bahwa kelas eksperimen berdistribusi normal. Setelah melakukan uji normalitas data kemudian dilakukan uji homogenitas data untuk melihat apakah data berdistribusi homogen atau tidak.

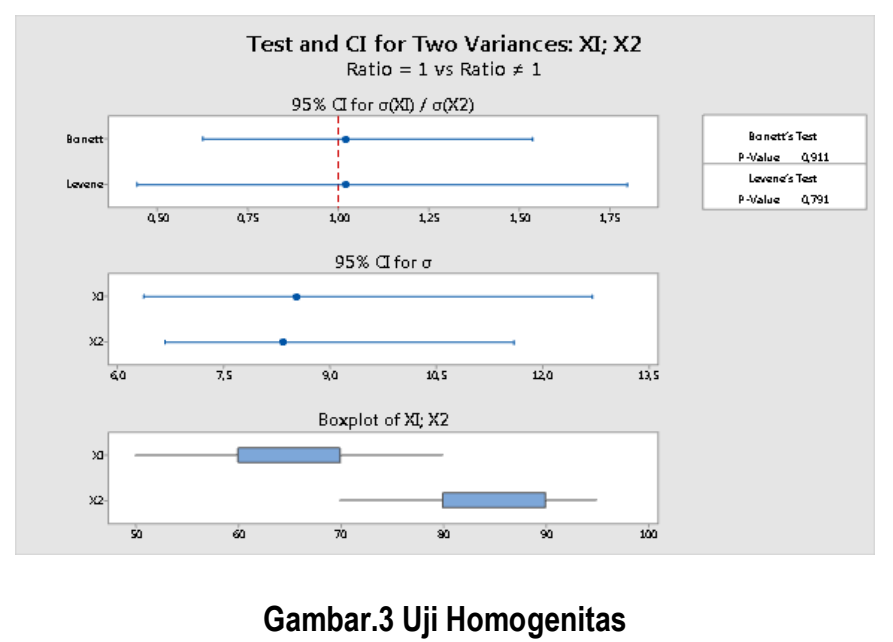

Berdasarkan tabel di atas nilai uji levene $0.791>0.05$ maka dapat disimpulkan bahwa kedua kelas homogen atau sama. Apabila uji prasyarat data sudah terpenuhi, maka dilakukan uji hipotesis dengan menggunakan uji $-t$. Dengan ketentuan apabila $t_{\text {hitung }}>t_{\text {tabel }}$ atau nilai $p$-value $<0.05$ nilai artinya hipotesis $\mathrm{H}_{0}$ ditolak dan hipotesis $\mathrm{H}_{1}$ diterima. Nilai tabel yang digunakan adalah 2.8609 .

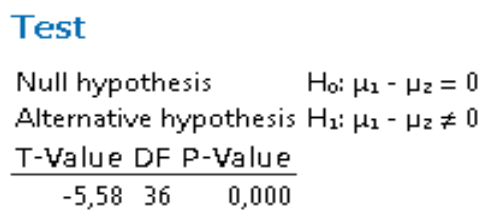

Gambar .4 Uji Hipotesis 
Pada tabel di atas menunjukan bahwa nilai T-value sebesar -5.58 atau nilai $p$-value $0.000<0.05$ maka dapat disimpulkan bahwa terdapat bahwa terdapat pengaruh signifikan antara model blended learning dengan hasil belajar zoologi mahasiswa. Penerapan model blended learning pada kelas eksperimen nilai rata-rata postest mahasiswa pada mata kuliah zoologi sebesar 83,42 dan nilai rata-rata postest pada kelas kontrol adalah 68,16. Data tersebut menunjukan bahwa model blended learning dapat meningkatkan hasil belajar siswa daripada model konvensional (Ayu \& Estika, 2017). Selain itu, pengunaan model pembelajaran blended learning yang lakukan di kelas secara tatap muka ataupun online dapat meningkatkan pemahaman konsep dan penalaran mahasiswa pada materi pelajaran (Hermawanto, et.al, 2013). Dalam pengujian hipotesis nilai T-value sebesar $-5.58<2.8609$ dan nilai $p$ value $0.00<0.05$ artinya hipotesis $\mathrm{H}_{0}$ ditolak dan hipotesis $\mathrm{H}_{1}$ diterima, maka dapat dismpulkan adanya penguruh yang signifikan antara penggunaan model blended learning terhdap hasil belajar mahasiswa pada mata kuliah zoologi.

Dalam pembelajaran online dengan model blended learning memiliki tampilan media yang menarik, mahasiswa bersemangat dan termotivasi dalam mengikuti pembelajaran dibandingkan dengan model lainnya (Sudiarta \& Sadra, 2016). Model pembelajaran blended learning mempunyai kelabihan , yakni mampu mendorong siswa dalam meningkatkan ketrampilan belajarnya, siswa mampu belajar kapan saja dan menjadi media yang efektif antara mahasiswa dan dosen dalam melakukan proses pembelajaran yang efektif dan efisien (Bahri et al., 2013). Akan tetapi, Model pembelajaran ini hanya mampu diterapkan pada sekolah maupun perguruan tinggi yang memiliki akses internet yang baik. Untuk itu dibutuhkan kreativitas bagi pendidik dan peserta dalam melakukan kegiatan belajar baik tata muka maupun elektronik (Herliani \& Sibarani, 2017). Model pembelajaran ini mampu meningkat pengendalian diri mahasiswa dalam proses belajar mengajar baik dengan tatap muka maupun online learning (Quinn \& Aarão, 2020). Dalam pelaksanaa model blended learning mampu meningkatkat semangat atau motivasi mahasiswa dalam belajar (Paringin, 2012). Apabila mahasiswa memiliki motivasi yang tinggi maka mempengaruhi hasil belajar dan prestasi mahasiwa dalam melaksankan pembelajaran zoologi. Kegiatan pembelajaran dengan blended learning akan sangat bagus untuk mendorong mahasiswa aktif dalam pencarian materi dan diskusi dengan temannya (Gede et al., 2019). Model pembelajaran diharapkan mampu meningkatkan kualitas pembelajaran di seklolah.

\section{KESIMPULAN}

Dari penelitian di atas menunjukan bahwa model blended learning efektif meningkatan hasil belajar mahasiswa pada mata kuliah zoologi dengan rata-rata 68.16 menjadi 83.42 . dan uji hipotesis didapatkan nilai $p$-value $0.000<0.05$ artinya adanya pengaruh signifikan model blenden learning terhadap hasil belajar mahasiswa pada materi zoologi.

\section{DAFTAR PUSTAKA}

Agus Susilo, A. S. (2020). Pembelajaran Sejarah Online Mahasiswa STKIP PGRI Lubuklinggau Di Masa Pandemik Covid 19. Urnal Pendidikan Sejarah Dan Riset Sosial Humaniora (KAGANGA), 3(1), 24-32.

Al-nofaie, H. (2020). Saudi University Students' Perceptions towards Virtual Education During Covid-19 Pandemic: A Case Study of Language Learning via Blackboard. Arab World English Journal (AWEJ), 11(September), 4-20.

Aowad, S., Shdaifat, K., Shdaifat, N. A. K., \& Khateeb, L. A. (2020). The Reality of Using E-Learning Applications in Vocational Education Courses During COVID 19 Crisis from the Vocational Education Teachers ' Perceptive in Jordan. International Education Studies, 13(10), 105-112. 
https://doi.org/10.5539/ies.v13n10p105

Bahri, A., Idris, I. S., \& Zaid, N. (2013). Efektivitas blended learning terintegrasi model pemetaan Bloom-Rederker-Guerra (B-R-G) memberdayakan self-regulated learning peserta didik. PROSIDING SEMINAR NASIONAL LEMBAGA PENELITIAN UNIVERSITAS NEGERI MAKASSAR, 417-421.

Carvalho, Í. N. De. (2020). How Should We Select Conceptual Content for Biology High School Curricula ? Science \& Education, 5(4), 1-35.

Chiou, H. (2018). The impact of situated learning activities on technology university students ' learning outcome. Ministry of Science \& Technology, 7(5), 1-13. https://doi.org/10.1108/ET-04-2018-0092 CIĞERCI, F. M. (2020). DISTANCE EDUCATION DURING THE COVID-19 PANDEMIC. International Online Journal of Primary Education, 9(1), 111-127.

Effendi, Z. M. (2017). The role of locus control and learning styles in the development of the blended learning model at PSU. International Journal of GEOMATE, 13(7), 75-80. https://doi.org/10.21660/2017.37.TVET025

Estika, Windy Ayu, E. (2017). PENGEMBANGAN BLENDED LEARNING DENGAN STRATEGI FLIPPED CLASSROOM PADA MATA PELAJARAN DESAIN MULTIMEDIA DI SMK PGRI PLOSO Windy Ayu Estika Ekohariadi. Jurnal IT-EDU, 2(2), 141-148.

Gede, D., Putra, A., Astawa, I. W. P., \& Ardana, I. M. (2019). Pengaruh model pembelajaran blended learning terhadap pemahaman konsep dan kelancaran prosedur matematis. Jurnal Riset Pendidikan Matematika, 6(1), 75-86.

Hermawanto1, S. Kusairi, W. (2013). Pengaruh Blended Learning terhadap Penguasaan Konsep dan Penalaran Fisika Peserta Didik Kelas X. Jurnal Pendidikan Fisika Indonesia, 9(57), 67-76.

lyengar, R. (2020). Education as the path to a sustainable recovery from COVID-19. PROSPECTS, 3-6. https://doi.org/10.1007/s11125-020-09488-9

Karakaya, F., Arik, S., Cimen, O., \& Investigation, M. (2020). Investigation of the Views of Biology Teachers on Distance Education during the COVID-19 Pandemic To cite this article : Investigation of the Views of Biology Teachers on Distance Education during the COVID-19 Pandemic. JOurnal of Education in Science, Environmet Adn Health, 6(4), 246-158. https://doi.org/10.21891/jeseh.792984

Kaya, H. (2020). Investigation of the effect of online education on eye health in Covid-19 pandemic. Int. J. Asst. Tools in Educ, 7(3), 488-496.

Koçoğlu, E., \& Tekdal, D. (2020). Analysis of distance education activities conducted during COVID-19 pandemic. Academic Journal, 15(9), 536-543. https://doi.org/10.5897/ERR2020.4033

Paringin, S. (2012). PENGARUH MODEL BLENDED LEARNING TERHADAP MOTIVASI THE INFLUENCE OF BLENDED LEARNING MODEL ON MOTIVATION AND ACHIEVEMENT Abstract : The Influence of Blended Learning Model on Motivation and Achievement of Vocational. Jurnal Pendidikan Vokasi, 2(2), 234-249.

Quinn, D., \& Aarão, J. (2020). Blended learning in first year engineering mathematics. ZDM, 6(6), 1-15. https://doi.org/10.1007/s11858-020-01160-y

Rini Herliani, C. G. G. T. S. (2017). PENERAPAN MODEL PEMBELAJARAN PROBLEM BASED LEARNING (PBL) BERBASIS BLENDED LEARNING UNTUK MENINGKATKAN MOTIVASI DAN HASIL BELAJAR AKUNTANSI. Urnal Teknologi Informasi \& Komunikasi Dalam Pendidika, 3(2), 194-198.

Sadikin, A., Hamidah, A., Pinang, K., JI, M., Ma, J., Km, B., Indah, M., Jaluko, K., Kode, K. M., \& Indonesia, P. (2020). Pembelajaran Daring di Tengah Wabah Covid-19 ( Online Learning in the Middle of the Covid-19 Pandemic ). BIODIK: Jurnal IImiah Pendidikan Biologi, 6(1), 214-224.

Sandi, G. (2012). PENGARUH BLENDED LEARNING TERHADAP HASIL BELAJAR KIMIA DITINJAU DARI KEMANDIRIAN SISWA. Jurnal Pendidikan Dan Pengajaran, 45(3), 241-251.

Sari, M. (2012). BLENDED LEARNING, MODEL PEMBELAJARAN ABAD ke-21 DI PERGURUAN TINGGI. Ta'dib, 17(2), 126-136.

Shen, K., Li, T., \& Lee, M. (2018). Learning biology as 'Increase ones ' knowledge and understanding ': 
studying Taiwanese high school students ' learning strategies in relation to their epistemic views and conceptions of learning in biology. International Journal of Science Education, 0(0), 1-21. https://doi.org/10.1080/09500693.2018.1522013

Sudiarta, I. G. P., \& Sadra, I. W. (2016). PENGARUH MODEL BLENDED LEARNING BERBANTUAN VIDEO ANIMASI TERHADAP KEMAMPUAN PEMECAHAN MASALAH DAN PEMAHAMAN KONSEP SISWA. Jurnal Pendidikan Dan Pengajara, 49(2), 48-58.

Sumardi, Arif Rohman, D. W. (2020). Does the Teaching and Learning Process in Primary Schools Correspond to the Characteristics of the 21 st Century Learning ? International Journal of Instruction, 13(3), 357-370.

T. Mailani , Zulfarina, W. S. (2020). Development of the PDEODE-WEB Model in Blended Learning to Improve the Students Critical Thinking Skills Development of the PDEODE-WEB Model in Blended Learning to Improve the Students Critical Thinking Skills. Journal of Physics: Conference Series, 1-6. https://doi.org/10.1088/1742-6596/1655/1/012054

Tanık-Önal, N. \& Önal, N. (2020). TEACHING SCIENCE THROUGH DISTANCE EDUCATION DURING THE COVID-19 PANDEMIC. International Online Journal of Education and Teaching (IOJET), 7(4), 1898-1911.

Yanti, F. N., \& Sugiharta. (2019). Analisis Kemampuan Pemecahan Masalah Matematis : Dampak Blended Learning Menggunakan Edmodo. Desimal: Jurnal Matematika, 2(2), 173-180. 